PROC. OF JSCE

No. 300, August 1980

\title{
PROPOSED DESIGN EQUATION FOR SHEAR STRENGTH OF REINFORCED CONCRETE BEAMS WITHOUT WEB REINFORCEMENT
}

\author{
By Hajime OKAMURA* and Takeshi HIGAI**
}

\begin{abstract}
A design equation for shear strength is proposed upon investigation of published test results on shear strengths of reinforced concrete beams without web reinforcement. The proposed equation is deduced based on experiments of beams failing in a diagonal tension mode and subjected to no axial force, and basically, this is also the range of application of the equation.

The equation has enough simplicity expressed by concrete strength, reinforcement ratio and effective depth in a cumulative form. The accuracy of the equation is acceptable since it is better than that of any other equations.
\end{abstract}

\section{INTRODUCTION}

Many experimental research works have been reported $^{1)}$ in regard to shear strength of reinforced concrete members. Regretably, however, a generally acceptable theory has not yet been established. After the development of flexural cracks shear force acting on a cracked section is carried by concrete in the compression zone, interlocking action of aggregates, and dowel action of longitudinal bars. The proportions shared by these actions have been clarified to a certain extent by experimental and analytical studies recently conducted ${ }^{2), 8)}$, but these results are not yet such as to be applicable to design use.

Nominal shear stress is generally used at present in design of reinforced concrete members without web reinforcement. Many test results have shown that the nominal shear stress at a critical diagonal cracking is principally dependent on concrete strength, reinforcement ratio, effective depth of cross section, shear span-depth ratio, and applied axial force. And a part or all of these

* Member of JSCE, Dr. Eng., Associate Professor of Civil Engineering, University of Tokyo.

** Member of JSCE, Dr. Eng., Associate Professor of Civil Engineering, University of Yamanashi. factors are included in design codes in some way. However, the effects of these factors are different according to the code or investigator.

Based on investigations of published test results, the authors have deduced a simple design equation for reinforced concrete members without web reinforcement. This equation includes the effects of all of the factors mentioned above, is supported by many test results, and is simple enough for ordinary design work.

\section{FACTORS USED IN THE PROPOSED EQU- ATION AND THEIR FUNCTIONAL EX- PRESSIONS}

\section{(1) Study on the principal factors}

The magnitude of axial force and shear spandepth ratio are also the principal factors influencing shear strength of reinforced concrete members, and it is well-recognized that shear strength increases considerably when the axial compressive force is applied or the shear span-depth ratio is small. However, this paper deals only with normal cases, that is, cases of shear span-depth ratios greater than about 3 and without axial forces at the first step.

The failure mode of a test beam without web reinforcement is mainly related to the shear spandepth ratio, and when the ratio is larger than about 3 , which is dealt with in this paper, the failure mode is usually so-called diagonal tension failure; a flexural crack in the middle of the shear span suddenly develops into a critical diagonal crack and shear failure occurs almost simultaneously with the development of this critical crack. The principal factors resisting development of the critical diagnoal crack are (1) tensile stress of concrete in the web, (2) interlocking action of aggregates across flexural cracks, (3) dowel action of longitudinal bars, and (4) shear stress of concrete in the compression zone. These factors are related to the strengths of the materials used and the crosssectional dimensions of the member.

a) Strength of concrete 
It is quite natural for diagonal cracking strength to be closely related to the principal tensile stress of concrete in the web and then to the tensile strength of concrete, and the shear strength without web reinforcement specified in the various codes is considered to be approximately proportional to the tensile strength of concrete. However, shear strength is usually expressed as a function of compressive strength of the concrete since it is not proper to use the tensile strength directly. Fig. 1 shows the relationships between shear strengths and compressive strengths in recent codes.4) 6) The compressive strengths in the figure are cylinder strengths with cub strength used in BSI CP110 multiplied by 0.85 .

The tensile strength of concrete is often considered to be proportional to the square root of the compressive strength. However, it is more proper to assume it to be proportional to the two thirds power of the compressive strength. The following equation was obtained from the results of tests carried out by the Cement Association of Japan. ${ }^{\text {) }}$

$$
f_{t}=0.27 f_{c}{ }^{2 / 3} \quad\left(f_{t} \text { and } f_{c}{ }^{\prime} \text { in } \mathrm{MPa}\right)
$$

Fig. 2 is derived from Fig. 1 by using Eq. (1). This figure appears to show that in these codes shear strength is approximately proportional to tensile strength. Although tensile strength of concrete prominently affects shear strength, this does not always mean that the tensile strength should be directly used in the equation for calculation of the shear strength. This is due to the fact that interlocking action of aggregates, dowel action of longitudinal bars, and shear resistance of concrete in the compression zone are closely related to the properties of concrete as described below. In fact, statistical studies ${ }^{8), 9)}$ shows that

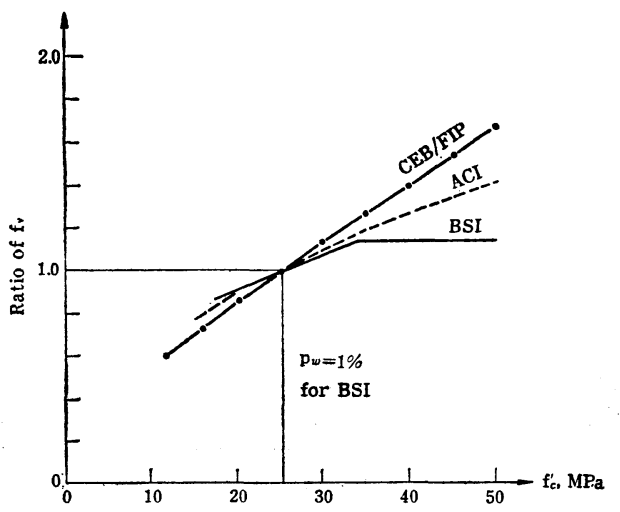

Fig. 1 The relationships between shear strengths $f_{v}$ and compressive strengths $f_{t}{ }^{\prime}$ of concrete in recent $\operatorname{codes}^{4) \sim(6)}$. shear strength is proportional to $1 / 2-1 / 3$ power of compressive strength.

b) Interlocking action of aggregates

It has already been clarified that in the case of a beam without web reinforcement the shear force carried by the interlocking action of aggregates across flexural cracks is large enough that it cannot be neglected. According to Fenwick and Paulay, ${ }^{2)}$ the interlocking action becomes larger as crack width is smaller or concrete strength is higher. The ratio of stress of tension reinforcement to the nominal shear stress is approximately constant if the position of applied load and the section of the beam are given, and this ratio is considered to be approximately inversely proportional to the reinforcement ratio. As the flexural crack width is approximately proportional to the stress of tension reinforcement, the crack width at the same stress level becomes smaller as the reinforcement ratio is increased. Moreover, it is known that crack width becomes smaller at the same stress level of reinforcement when the amount of tension reinforcement is relatively large compared with the area of concrete in the tension zone. These facts indicate that the interlocking action will increase when the reinforcement ratio is large. And it is naturally expected that the interlocking action will increase when the strength of the mortar, which supports the coarse aggregates, is high.

The above discussion is based on the assumption that the ratio between the dimension of aggregates and those of the cross section is fixed. The relative relation between the maximum size of aggregates and the dimensions of the cross section affects the contribution of the interlocking action. Taylor ${ }^{10}$ has shown based on his experiments in which depths of beams and the sizes of aggregates were changed that the main reason for high shear strength of a small

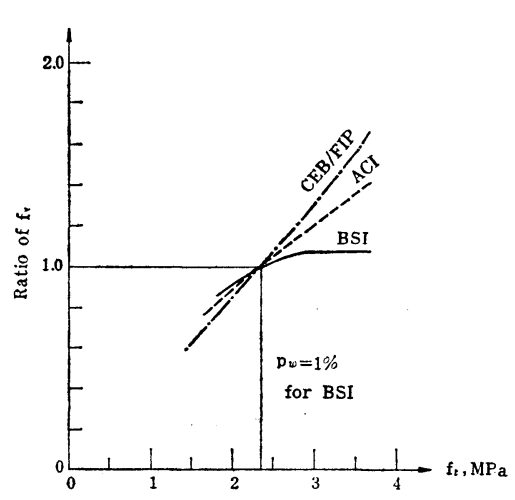

Fig. 2 The relationships between shear strengths $f_{v}$ and tensile strengths $f_{l}$ of concrete in recent.codes derived from Fig. 1. 
specimen is the relatively large aggregate size for the depth of the beam and the consequently large interlocking action in the small specimen, and that the strength of the small specimen would not be very different from that of a large specimen if the aggregate size were to be scaled down properly. Since in ordinary reinforced concrete members the maximum size of aggregates is usually not changed much even when the dimensions of the members differs markedly, the shear strengths of members with large depths might be reduced, and this effect should be taken into consideration in design.

c) Dowel action of longitudinal bars

A part of the shear force can be transfered by the dowel action of longitudinal bars. The main factors influencing this action are flexural rigidities of the bars, and strength and rigidity of the surrounding concrete. In more concrete terms, area, diameter, number and arrangement of the bars, spacing of flexural cracks, and tensile strength and elastic modulus of concrete are considered to be the main factors. However, the contribution of each of these factors has not yet been separately expressed. Moreover, it is not practical to include all these factors in the design equation. Under present circumstances it is more realistic to judge the magnitude of dowel action by using the reinforcement ratio and tensile strength or compressive strength of concrete as the main factors.

d) Shear resistance of concrete in the compression zone

After the development of flexural cracks, a part of shear is carried by the concrete in the compression zone, and this is closely related to the area of compression zone. As the position of the neutral axis after flexural cracking depends mainly upon the elastic modulus of concrete and the reinforcement ratio, shear carried by the concrete in the compression zone is considered to be defined by the reinforcement ratio and the strength of concrete since the elastic modulus is to be the function of concrete strength.

\section{(2) Functional expression of the principal factors}

As discussed in section 2.(1), it is considered that (1) aggregate interlocking action is affected by compressive strength of concrete, reinforcement ratio, effective depth of cross section, and ratio of moment to shear, (2) dowel action is affected by concrete strength, reinforcement ratio, and ratio of moment to shear, and (3) shear resistance of concrete in the compression zone is affected by concrete strength and reinforcement ratio.

Fig. 3 shows recent test results ${ }^{8), 9), 11), 12)}$ con-

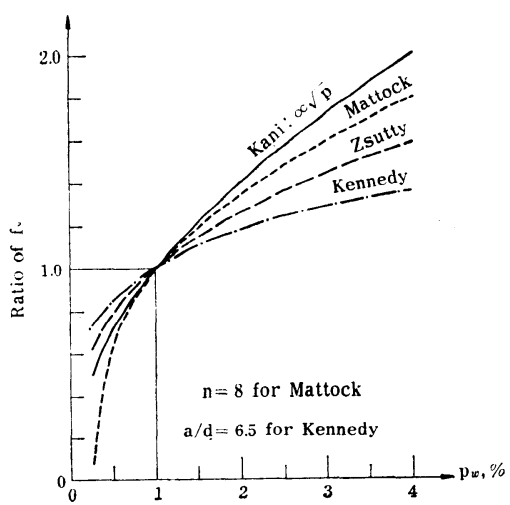

Fig. 3 The relationships between shear strengths $f_{v}$ and reinforcement ratio $p_{w}$ in recent investigations ${ }^{8), 9), 11), 12) . ~}$

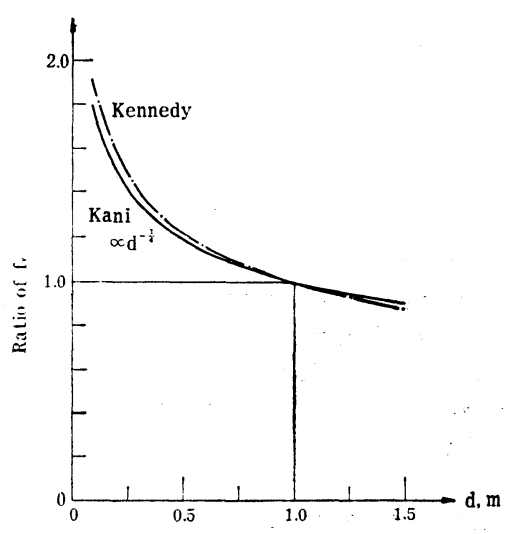

Fig. 4 The relationships between shear strengths $f_{v}$ and effective depth $d$ in recent investigations ${ }^{9), 11)}$.

cerning the relationship between shear strength and reinforcement ratio. The simple expression may be Kani's one in which shear strength is proportional to the square root of the reinforcement ratio.

As the effect of the absolute value of effective depth on shear strength is considerably great as shown in Fig. $\mathbf{4}^{9)}$,11), this should be taken into account. The most simple expression is the one proposed by Kani, that is, shear strength is proportional to one-fourth power of effective depth, and this is considered to be appropriate.

The effect of concrete strength is rather complicated. If the effect of tensile strength is considered to be dominant, shear strength may be proportional to two-thirds power of the compressive strength of concrete. On the other hand, one-third power may be usable if the effect of concrete strength on the interlocking action of aggregates is emphasized as proposed by Placas and $\operatorname{Regan}^{13)}$. 


\section{PROPOSED EQUATION AND ITS EVALU- ATION}

\section{(1) Expression of the proposed equation}

Many of the equations proposed for estimating shear strength have been as products of main factors such as concrete strength and reinforcement ratio. However, product form equations will give extreme values of shear strength if more than two variables were to take extreme values. The authors believe that such tendencies are not found in real cases. Therefore, it was decided to use a sum form in principle. According to the discussions in section 2, reinforcement ratio $p$, effective depth $d$ and compressive strength of concrete $f_{c}^{\prime}$ are used as the variables in the proposed equation to estimate the nominal shear strength $f_{v}$ of reinforced concrete members without web reinforcement.

$$
\begin{aligned}
& f_{v} / f_{t}=\beta_{0}\left(1+\beta_{p}+\beta_{d}\right) \\
& \beta_{p}=\sqrt{p_{w}}-1 \quad\left(p_{w} \text { in } \%\right) \\
& \beta_{d}=1 / \sqrt[4]{d}-1 \quad(d \text { in } \mathrm{m})
\end{aligned}
$$

$\beta_{0}$ : constant

$f_{v}$ : nominal shear strength of beam without web reinforcement

$$
=V_{o} /\left(b_{w} d\right), \mathrm{MPa}
$$

$f_{t}$ : tensile strength of concrete $=0.27 f_{c}{ }^{2 / 3}$, $\mathrm{MPa}$

$p_{w}:$ reinforcement ratio $=100 A_{s} /\left(b_{w} d\right), \%$

$d:$ effective depth, $\mathrm{m}$

$b_{w}$ : width of web

$V_{c}$ : shear force at failure of beam $f_{c}{ }^{\prime}$ : compressive strength of concrete, $\mathrm{MPa}$

$A_{s}$ : area of tension reinforcement

The reasons why ratio of moment to shear or shear span-depth ratio is not included as a variable are that the effect is not great in the range treated in this paper, and it is not always appropriate to use the ratio in the practical design equations. ${ }^{14)}$

\section{(2) Determination of $\beta_{0}$}

In order to determine the constant $\beta_{0}$ in Eq. (2), the authors used the published test data listed in Table 11),12),15) 29). These data were selected considering the following:

(1) More than five data with shear span-depth ratio greater than 3 or showing failure in the diagonal tension mode are to be included.

(2) More than two factors among reinforcement ratio, effective depth, shear span-depth ratio and compressive strength of concrete are more or less constant.

The investigation based on these data indicated that the values of calculated by Eq. (5) was nearly constant for the wide range of $p_{w}$ and $d$.

$$
\beta_{0}=\left(f_{v} / f_{t}\right) /\left(1+\beta_{p}+\beta_{d}\right)
$$

However, a clear trend was recognized concerning the compressive strength of concrete. The calculated values of $\beta_{0}$ for small $f_{c}^{\prime}$ were obviously larger compared with those for large $f_{\mathrm{c}}^{\prime}$ if $\beta_{0}$ is treated as constant. This was considered to be due to the fact that tensile strength,

\begin{tabular}{|c|c|c|c|c|c|}
\hline & Number & $\begin{array}{c}f_{c^{\prime}}^{\prime} \\
(\mathrm{MPa})\end{array}$ & $\left(\begin{array}{l}p \\
\%\end{array}\right)$ & $\underset{(\mathrm{m})}{d}$ & $a / d$ \\
\hline Kani11) & 31 & $25-31(27.0)$ & $2.6-2.9(2.73)$ & $0.13-1.10(0.44)$ & $2.6-8.0(4.71)$ \\
\hline Morrow ${ }^{15}$ ) & 11 & $15-46(29.9)$ & $1.2-3.8(2.26)$ & $0.34-0.36(0.35)$ & $3.8-7.9(4.70)$ \\
\hline Mathey 16$)$ & 7 & $24-31(26.2)$ & $0.5-0.9(0.75)$ & 0.403 & $2.8-3.8(3.37)$ \\
\hline $\left.\mathrm{Kani}^{17}\right)$ & 13 & $18-35(27.1)$ & $0.5-0.8(0.71)$ & $0.27-0.27(0.27)$ & $3.0-5.1(3.51)$ \\
\hline Rajagopalan ${ }^{18}$ ) & 10 & $25-37(29.8)$ & $0.3-1.7(0.75)$ & $0.26-0.27(0.27)$ & $3.9-4.3(4.14)$ \\
\hline Diaz de Cossio ${ }^{19}$ & 22 & $14-29(23.8)$ & $1.9-2.9(2.18)$ & $0.08-0.17(0.11)$ & 4.00 \\
\hline Krefeld ${ }^{20}$ ) & 53 & $12-39(24.6)$ & $1.1-4.5(3.06)$ & $0.24-0.48(0.26)$ & $3.6-8.5(5.28)$ \\
\hline Moody 21 & 24 & $12-41(26.0)$ & $0.8-2.4(1.90)$ & $0.26-0.27(0.27)$ & $2.9-3.4 \quad(3.26)$ \\
\hline Chang22, & 12 & $31-39(33.0)$ & $1.9 \cdot 2.9(2.38)$ & 0.137 & 3.72 \\
\hline Mattock 12 & 6 & $16.47(24.3)$ & $1.03 .1(2.24)$ & 0.254 & $3.0-5.4(4.20)$ \\
\hline Van den Berg 23 & 34 & $15 \cdot 66(34.5)$ & 4.35 & 0.359 & $3.54 .9(3.78)$ \\
\hline Leonhardt 21 ) & i & $30.31(30.6)$ & $2.0-2.1(2.04)$ & $0.27-0.28(0.28)$ & $3.0-5.9(4.76)$ \\
\hline Leohnardt 25 ) & 12 & $35-39(37.9)$ & $1.3-1.7(1.55)$ & $0.07-0.60(0.24)$ & 3.00 \\
\hline Taylor 26$)$ & 23 & $19-37(26.3)$ & $0.9-2.3(1.70)$ & 0.222 & 4.11 \\
\hline Taylor 27$)$ & 12 & $24-32(27.3)$ & $1.2-1.9(1.43)$ & $0.22-0.22(0.22)$ & $3.8-3.8(3.78)$ \\
\hline Aster 28) & 5 & $28-28(27.9)$ & $0.4-0.9(0.62)$ & $0.50-0.75(0.45)$ & 3.70 \\
\hline Higai29) & 7 & $31-37(32.9)$ & 2.39 & 0.160 & $3.5-6.5(4.36)$ \\
\hline Total & 288 & $12-66$ & $0.3-4.5$ & $0.07-1.10$ & $2.6-8.5$ \\
\hline
\end{tabular}
which was applied to take into account the effect of concrete, could not properly cover the total contribution of concrete strength. Therefore, in

Table 1 Outline of data used; range (and average) of parameters. 

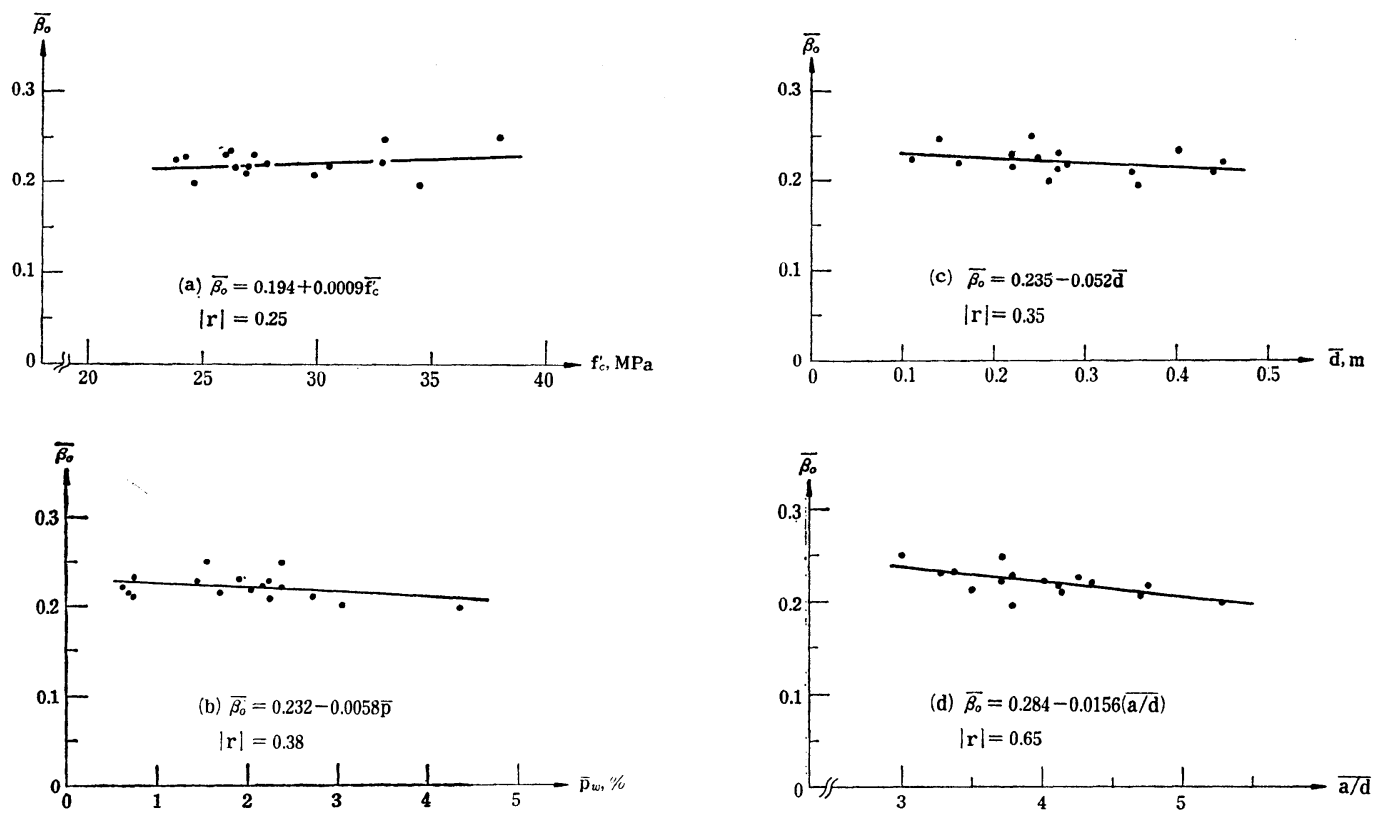

Fig. 5 The relationships between $\bar{\beta}_{0}$ calculated by Eq. (5) and each parameter $\left(\bar{\beta}_{0}, \bar{f}_{c^{\prime}}, \bar{p}_{w}, \bar{d}\right.$ and $\overline{a / d}$ are averages in Table 1$)$.

the next step Eq. (6) was used to express the contribution of concrete strength, and an investigation based on Eq. (7) was carried out.

$$
\begin{aligned}
& f_{0}=f_{c}{ }^{1 / 3} \quad\left(f_{0} \text { and } f_{c}{ }^{\prime} \text { in MPa }\right) \\
& f_{v} / f_{0}=\beta_{0}\left(1+\beta_{p}+\beta_{d}\right) \ldots \ldots \ldots \ldots \ldots \ldots \ldots \ldots
\end{aligned}
$$

Where, $f_{0}$ is not any kind of strength of concrete, but an interpretation of all the contributions by the quality of concrete, which includes tensile strength and influences of aggregate interlocking and dowel action.

The coefficient of variation of $\beta_{0}$ calculated by Eq. (7) concerning the data in Table 1 is $12.5 \%$ with an average of 0.216 . This means that the coefficient of variation for the ratios of the shear strengths tested to that calculated with $\beta_{0}$ of 0.216 is also $12.5 \%$ and the accuracy of this equation may be considered to be satisfactory.

Detailed discussions on the influences of the individual variables are as follows. The ranges of the variables in each data group are shown in Table 1 together with the averages. Fig. 5 shows the relationship between the averages of the individual variable within each group and the calculated average $\beta_{0}$ for each group. No special trend of average is seen about $f_{c}{ }^{\prime}$ or $d$, and $p_{w}$ unless $\boldsymbol{p}_{w}$ is larger than $3 \%$. Some of the groups with $p_{w}$ larger than $3 \%$ show tendencies for smaller $\beta_{0}$. Concerning shear span-depth ratio, Fig. 5 (d) shows that the larger the ratio the smaller the $\beta_{0}$ value. Therefore, $p_{w}$ is limited to under $3 \%$ in the first place, and the authors recalculated $\beta_{0}$ by using $\boldsymbol{p}_{w}=3 \%$ if $\boldsymbol{p}_{w}$ was larger than $3 \%$. The coefficient of variation of $\beta_{0}$ was $11.3 \%$ and this was about $1 \%$ less than that without limitation of $p_{w}$. This limitation of $p_{w}$ was considered effective.

In the next place, data with wide range of shear span-depth ratios such as Kani11), Morrow $^{15)}$, Krefeld ${ }^{20)}$, Mattock ${ }^{12)}$, Leonhardt ${ }^{24), 25)}$ and $\mathrm{Higai}^{29)}$ were investigated. The effect of the ratio in these data was recognized to have two different treads. One was the trend seen in the data by Morrow, Krefeld, Mattock, and a part of the data by Kani, and $\beta_{0}$ is clearly reduced as the ratio is increased as shown in Fig. 6 (a) which gives a part of Kani's data. On the other hand, test data obtained by Leonhardt and Higai, and a part of the data by Kani show that $\beta_{0}$ is nearly constant for the wide range of shear span-depth ratio as indicated in Fig. 6 (b). Since the reason for these differences was not clarified, it is rather difficult to obtain a modified equation which gives a better result for all the data. Therefore, for the time being, the relation between $\beta_{0}$ and shear span-depth ratio was assumed to be expressed by the following equation.

$$
\begin{array}{r}
\beta_{0}=A+B(d / a) \\
a: \quad \text { shear span } \\
A, B: \text { constant }
\end{array}
$$

The constant $A$ and $B$ were determined by applying the method of least squares to the data above. $A$ was 0.157 and $B$ was 0.257 with a 

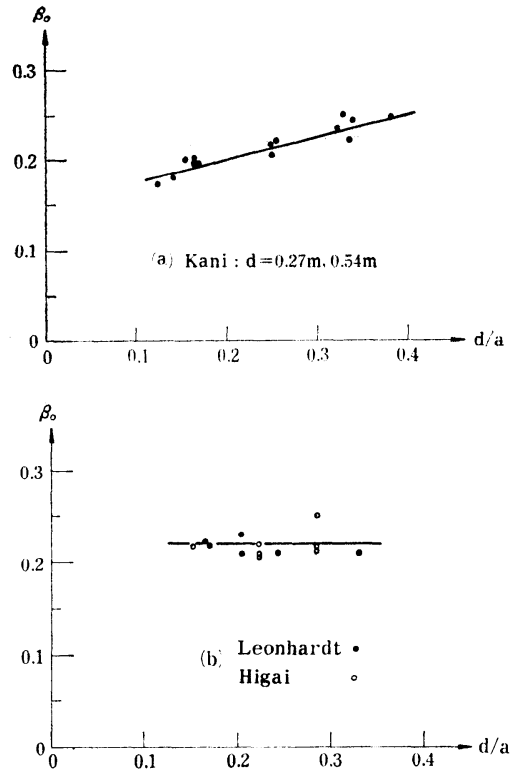

Fig. 6 The relationships between $\beta_{0}$ and $a / d$ in the typical data ${ }^{11), 24), 29)}$

coefficient of correlation of 0.721 and the number of data of 114. Considering these results and the average value of $\beta_{0}$ for all of the data used, $\beta_{0}$ was finally determined to be expressed by the following equation.

$$
\beta_{0}=0.20(0.75+1.4 d / a)
$$

When the shear strength was calculated for all of the data $(n=288)$ applying Eq. (9), the average of the ratios of shear strengths tested to that calculated was 1.00 and the coefficient of variation was $9.2 \%$. This variation is equivalent to that of compressive strength or tensile strength of concrete. And this modification has not shown poorer applicability to any group of data as indicated in Table 2 . The average ratios regarding the data within each paper are between 0.92 and 1.10 , and moreover in 15 papers out of 17 the ratios are between 0.97 and 1.03. After these considerations, the authors proposed Eq. (10) to calculate shear strengths of reinforced concrete members without web reinforcement.

$$
\begin{aligned}
& f_{v}=f_{v 0}(0.75+1.4 d / a)\left(1+\beta_{p}+\beta_{d}\right) \\
& f_{v 0}=0.20 f_{c}{ }^{1 / 3} \quad\left(f_{v 0} \text { and } f_{c}{ }^{\prime} \text { in } \mathrm{MPa}\right) \\
& \beta_{p}=\sqrt{\boldsymbol{p}_{w}}-1: p_{w} \leq 3 \%\left(\boldsymbol{p}_{w} \text { in } \%\right) \\
& \beta_{d}=d^{-1 / 4}-1: d \leq 1.1 \mathrm{~m}(d \text { in } \mathrm{m})
\end{aligned}
$$

where, $f_{v 0}$ has a dimension of strength, and is defined as the shear strength of the beam with $a / d$ of $5.6, p_{w}$ of $1 \%$ and $d$ of $1 \mathrm{~m}$.

\section{(3) Evaluation of the proposed equation}

Many equations for calculating shear strengths of reinforced concrete members have been proposed, and they may be classified into three categories:

(1) so-called theoretical equations introduced by assuming the failure mechanism,

\begin{tabular}{|c|c|c|c|c|c|}
\hline \multirow{2}{*}{ Data form } & \multicolumn{5}{|c|}{ Average (coefficients of variation, $\%$ ) } \\
\hline & Eq. (10) & Eq. (11) & Eq. (12) & Eq. (13) & Eq. (14) \\
\hline Kani11 & $0.98(8)$ & $1.03(15)$ & $1.12(8)$ & $1.04(11)$ & $1.06(10)$ \\
\hline Morrow ${ }^{15}$ ) & $1.00(5)$ & $0.99(4)$ & $1.06(7)$ & $0.93(11)$ & $1.06(8)$ \\
\hline Mathey ${ }^{16)}$ & $0.99(5)$ & $0.90(4)$ & $0.90(5)$ & $0.97(6)$ & $1.17(6)$ \\
\hline $\mathrm{Kani}^{17}$ & $0.92(10)$ & $0.93(10)$ & $0.83(12)$ & $0.91(21)$ & $1.07(13)$ \\
\hline Rajagopalan $^{18}$ ) & $0.97(14)$ & $0.99(14)$ & $0.85(12)$ & $0.82(12)$ & $1.05(14)$ \\
\hline Diaz de Cossio(9) & $1.01(15)$ & $1.30(18)$ & $0.99(12)$ & $1.03(15)$ & $1.12(14)$ \\
\hline Krefeld20) & $1.01(6)$ & $1.06(7)$ & $1.09(6)$ & $0.99(12)$ & $1.05(11)$ \\
\hline Moody'21 & $0.98(9)$ & $1.03(9)$ & $1.03(9)$ & $0.98(11)$ & $1.16(10)$ \\
\hline Chang 22 , & $1.10(8)$ & $1.32(7)$ & $1.09(7)$ & $1.08(10)$ & $1.24(7)$ \\
\hline Mattock 12 & $1.02(\mathrm{f})$ & $1.10(5)$ & $1.09(7)$ & $1.05(11)$ & $1.14(15)$ \\
\hline Van den Berga3, & $1.03(6)$ & $0.94(6)$ & $1.11(5)$ & $1.12(7)$ & $1.16(6)$ \\
\hline Leonhardt 24 ) & $1.03(10)$ & $1.09(10)$ & $1.06(9)$ & $0.88(3)$ & $1.09(4)$ \\
\hline Leonhardt ${ }^{25}$, & $1.03(7)$ & $1.15(19)$ & $0.98(6)$ & $1.04(11)$ & $1.25(7)$ \\
\hline Taylor $\left.{ }^{26}\right)$ & $0.99(8)$ & $1.07(8)$ & $0.98(7)$ & $0.91(9)$ & $1.08(8)$ \\
\hline Taylor 27 & $1.02(13)$ & $1.10(12)$ & $0.99(11)$ & $0.96(15)$ & $1.14(13)$ \\
\hline Aster ${ }^{28}$ ) & $0.98(6)$ & $0.87(7)$ & $0.84(7)$ & $0.88(5)$ & $1.10(6)$ \\
\hline Higai29) & $1.01(7)$ & $1.20(7)$ & $1.02(7)$ & $0.94(7)$ & $1.10(6)$ \\
\hline Total & $1.00(9.2)$ & $1.06(15.5)$ & $1.03(11.4)$ & $0.99(13.7)$ & $1.11(11.3)$ \\
\hline
\end{tabular}

(2) so-called empirical equations introduced by finding the main factors from test results

Table 2 Averages and coefficients of variation within each paper of the ratios of shear strengths tested to those calculated by the various equations. 

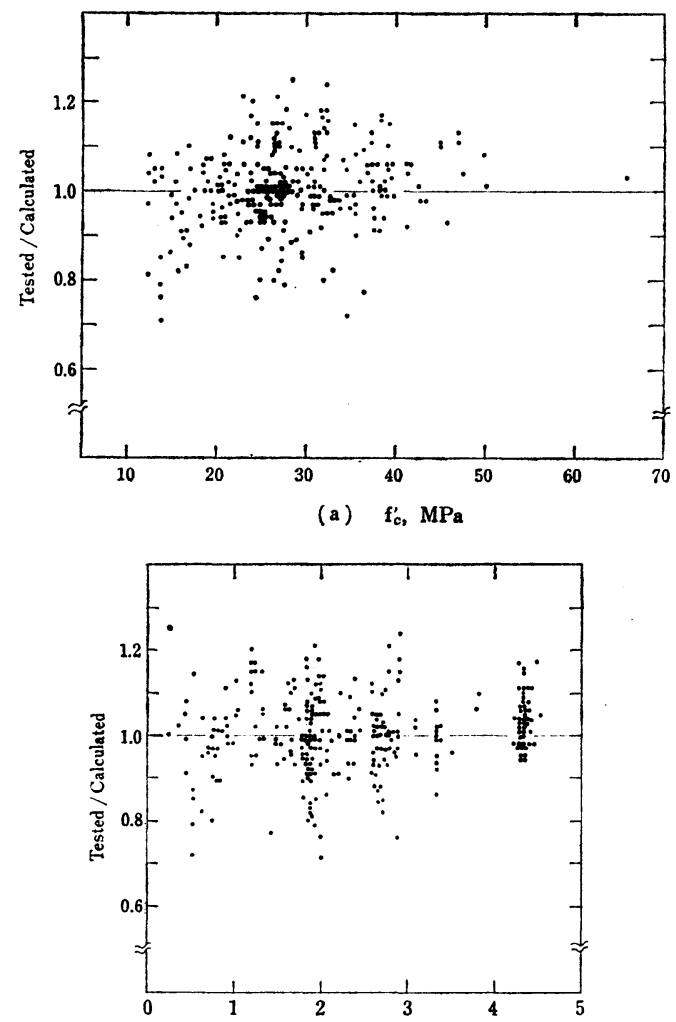

(b) $\mathrm{p}_{\mathrm{w}}, \%$
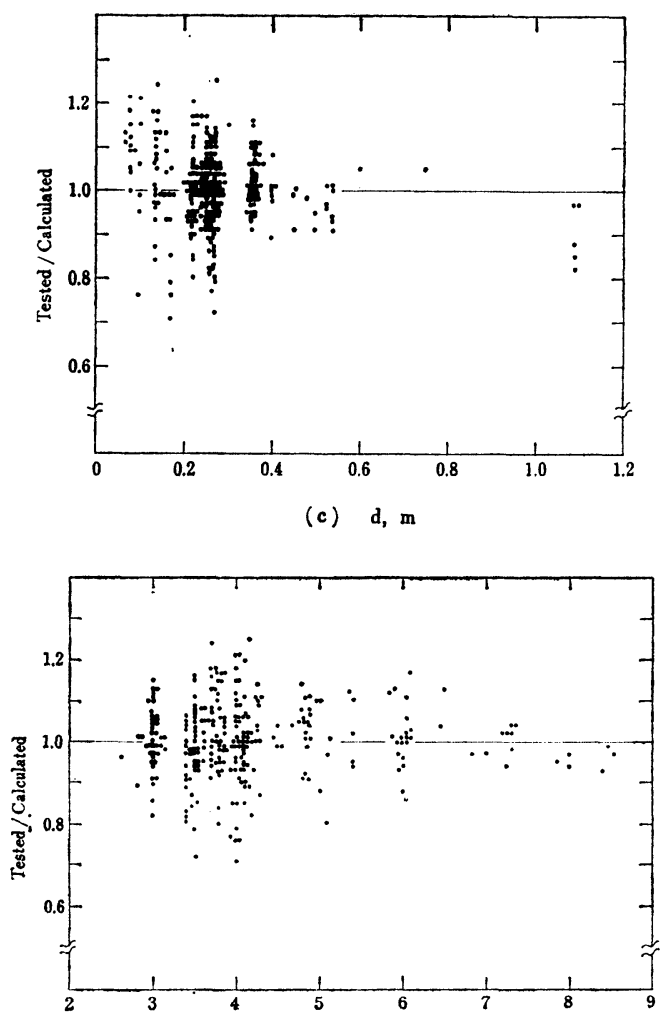

(d) $a / d$

Fig. 7 The relationship between the ratio of shear strength tested to that calculated by Eq. (10) and the value of each variable.

and determining the format of the equation and the constants in the equation from the test results, and

(3) equations introduced by statistical analyses of many published test data.

If the failure mechanism and the properties of materials are well-understood, Category (1) is to be applied for the widest range. However, it is considered that this type of equation is not yet applicable to test data with sufficient accuracy. Equation in Category (2) will naturally agree with test results which comprise the basis of the equation, but they do not agree so well with other test data where the range of variables are different. This is one of the reasons why many empirical equations have been proposed. Therefore, in introducing this kind of equation, selection of the test data to be used is quite important. In Category (3) a statistical method such as multi-regression analysis is applied to analyze the experimental data, and it agrees relatively well with the test results if the format of the equation and the data used are appropriate. However, the meanings of the variables in the equation usually are not clear.
The equation proposed by the authors is considered to belong to Category (2). Therefore, careful selection of data was carried out considering that the variables should cover entire range used in ordinary structures as mentioned in section 3.(2). Finally, 288 data, which cover a sufficient range of parameters such as concrete strength, reinforcement ratio, and shear span-depths ratio were obtained, although the range of depths is not sufficient. The relationship between the ratio of shear strength tested to that calculated by Eq. (10) and the value of each variable used are shown in Fig. 7. Compressive strengths of concrete $f_{c}{ }^{\prime}$ are in the range from $12 \mathrm{MPa}$ to $66 \mathrm{MPa}$, and in most data they are between $20 \mathrm{MPa}$ and $40 \mathrm{MPa}$. No special relation is seen in Fig. 7 (a) between the ratio and compressive strength of concrete. The reinforcement ratios are between $0.25 \%$ and $4.5 \%$. And no special relation is seen within this range. The effective depth of sections range from $0.07 \mathrm{~m}$ to $1.1 \mathrm{~m}$, and in most of the data the effective depths are less than $0.35 \mathrm{~m}$. Although the data. for large depths is insufficient to show the tendency of the ratio when the effective depth is 
Table 3 Average and coefficient of variation of the ratios of shear strengths tested to those calculated by Eq. (10).

\begin{tabular}{l|r|r|r}
\hline & Number & Average & C.V.* \\
\hline$f_{c^{\prime}}<20 \mathrm{MPa}$ & 40 & 0.96 & 10.1 \\
$20 \leq f_{c^{\prime}}<35$ & 190 & 1.01 & 9.2 \\
$f_{e^{\prime}} \geq 35 \mathrm{MPa}$ & 58 & 1.03 & 7.4 \\
\hline$p<1.5 \%$ & 59 & 1.00 & 10.7 \\
$1.5 \leq p<3.0$ & 163 & 1.00 & 9.6 \\
$p \geq 3.0 \%$ & 66 & 1.03 & 6.1 \\
\hline$d<0.2 \mathrm{~m}$ & 53 & 1.03 & 11.7 \\
$0.2 \leq d<0.4$ & 207 & 1.00 & 8.5 \\
$d \geq 0.4 \mathrm{~m}$ & 28 & 0.97 & 6.2 \\
\hline $\boldsymbol{a} / d<3.5$ & 61 & 0.98 & 8.7 \\
$3.5 \leq a / d<5.5$ & 190 & 1.01 & 9.7 \\
$a / d \geq 5.5$ & 37 & 1.00 & 6.6 \\
\hline
\end{tabular}

* Coefficient of variation

changed, no special trend is recognized in the data used. The range of shear span-depth ratios is between 3 and 8.5 , and no significant trend is seen concerning the average and the variation in this range. However, the variation of the ratios are obviously different according to the values of $f_{c}^{\prime}, p_{w}$ or $d$ as indicated in Table 3 . The variations become larger when the concrete strength, reinforcement ratio or effective depth becomes smaller, although the average ratios are more or less same. This result is to be expected when the applicability of Eq. (10) is good. These discussions show that the proposed equation may be considered to be appropriate in the selection of the principal factors and in expression of these factors.

The authors have proposed an equation in consideration of obtaining an equation of sufficient simplicity and applicability for the experimental results available, and this purpose is considered to have been well-achieved. However, there are many equations already proposed and it is thought necessary for comparisons to be made with these equations. From among the equations in Category (3), the well-known Zsutty's equation $^{8)}$ and Kennedy's equation ${ }^{9)}$ deduced by multiple regression analysis, and HedmanLosberg's equation ${ }^{30}$, which is the basis of the equation in the CEB/FIP Model Code, were selected for comparison.

$$
\begin{aligned}
& \text { Zsutty: } \\
& \quad f_{v}=0.476\left(f_{c}^{\prime} p_{w} d / a\right)^{1 / 3}
\end{aligned}
$$

Kennedy:

$$
f_{v}=0.312 f_{c}^{\prime 0.426} d^{-0.282}\left(1+\frac{M / V d}{0.25 p}\right)^{-0.244}
$$

Hedman-Losberg:

$$
\begin{aligned}
& f_{v}=0.09(1.75-1.25 d)\left(1+50 p_{w}\right) \sqrt{f_{c}^{\prime}} \cdots \cdots(13) \\
& 1.75-1.25 d \geq 1.0 \\
& p_{w} \leq 0.02
\end{aligned}
$$

These equations are also expressed in terms of SI units. Eq. (11) or Eq. (13) is the same as that proposed by Zsutty or Hedman-Losberg while Eq. (12) is that for beams without compression reinforcement as proposed by Kennedy.

The ratio of all test values of shear strength in Table 1 to those calculated by Zsutty's, Kennedy's or Hedman-Losberg's equation are.. as shown in Table 2. The average ratios of shear strengths tested to that calculated are 1.06, 1.03 and 0.99 , and the coefficients of variation are $15.5 \%, 11.4 \%$ and $13.7 \%$, respectively. The equation proposed by the authors with coefficient of variation $9.2 \%$ is considered to be better than these equations with respect to accuracy and simplicity. Data used in Zsutty's analysis have small range of depth, while he has neglected the effect, which is now known to be one of the main factors. Therefore, his equation estimates the strength to be higher when depth is larger. The relatively high coefficient of variation by Kennedy's equation is due to the fact that the variation in the average for each data group is somewhat large. It may be one of the reason why the coefficient of variation by Hedman's equation is relatively larger that the equation neglects the effect of shear span-depth ratio. However, the coefficient is still larger than that obtained by Eq. (14), which is derived from Eq. (10) by neglecting the effect of shear span-depth ratio.

These discussions are based on the data collected by the authors. Therefore, comparisons based on the data used in original analyses are also made. The data used in Zsutty's work are from the experiments by Diaz de Cossio, Moody, Morrow, Van den Berg and Kani. According to Zsutty's paper, the coefficient of variation of the ratios of shear strengths to the calculated one was $8.6 \%$ for the 86 beams with shear spandepth ratios larger than 2.5. The authors, however, obtained 94 data from the reports. As it was not clear which data Zsutty excluded, these 94 data were used in comparisons. The average of the ratios of shear strengths tested to that calculated is 1.00 with the coefficient of variation $13.2 \%$ by Zsutty's equation, while the average is 0.99 and the coefficient of variation $10.0 \%$ by the authors' proposed equation. With regard to these data Eq. (10) is again considered to be better than Zsutty's equation. In the data collected by Kennedy, simply supported beams with shear span-depth ratios larger than 3 were those from Diaz de Cossio, 
Moody, Chang, Hanson, Maclarnon, Gaston, Krefeld, and Bresler. Regarding the above 107 data, the ratio of shear strength tested to that calculated is 1.06 by Kennedy's equation and 1.00 by Eq. (10), and the coefficients of variation are $12.3 \%$ and $10.0 \%$, respectively. Hedman \& Losberg have deduced their equation based on 255 data obtained from 15 papers, and the coefficient of variation of the ratio of shear strengths tested to those calculated is $16 \%$. The authors could collect 157 data among them. The coefficients of variation about these 157 data are $13.8 \%$ by Hedman's equation and $10.1 \%$ by Eq. (10). These comparisons show the same trend as the results given in Table 2 , and it is substantiated that Eq. (10) even better fits the data which are the bases of other typical equations.

\section{DESIGN EQUATION AND ITS APPLICA- TION}

\section{(1) Design equation}

It is desirable for a design equation to be as simple as possible so long as it maintains acceptable accuracy. And it should not be one which gives the average strength such as Eq. (10), but should be a more conservative one which takes into account variations. Eq. (10) is relatively simple, but it is difficult to define shear spandepth ratios properly for such as which sustain distributed loads or moving loads, or for statically indeterminate structures such as continuous beams. Shear strength is markedly affected by shear span-depth ratio only under a certain loading condition that the load is acting on the top surface and the reaction is from the bottom surface, and then the vertical compressive stress is developed in the web concrete. Under this condition the shear strength increases significantly if the shear span-depth ratio becomes lower than three. Therefore, a rational design method for such conditions should be developed separately since the authors' proposed euqation does not cover. Except for such conditions the effect of the shear span-depth ratio can be neglected for the design equation without significant loss of accuracy. With these considerations, the authors propose here a design equation for shear strength of reinforced concrete beams without web reinforcement.

$$
f_{v}=f_{v 0}\left(1+\beta_{p}+\beta_{d}\right)
$$

Eq. (14) is given by substituting 5.6 for $a / d$ in Eq. (10). Therefore, this equation gives a more conservative value in case of $a / d$ smaller than 5.6. Actually, the average of the ratios of shear strengths with $a / d$ smaller than 5.6 to that calculated by Eq. (14) is 1.13 with coefficient of

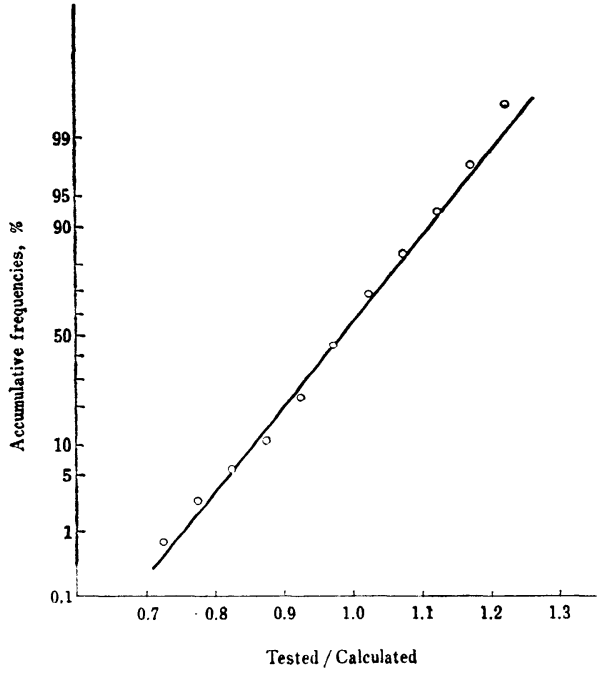

Fig. 8 Accumulative frequencies of the ratio of shear strength tested to that calculated by Eq. (10).

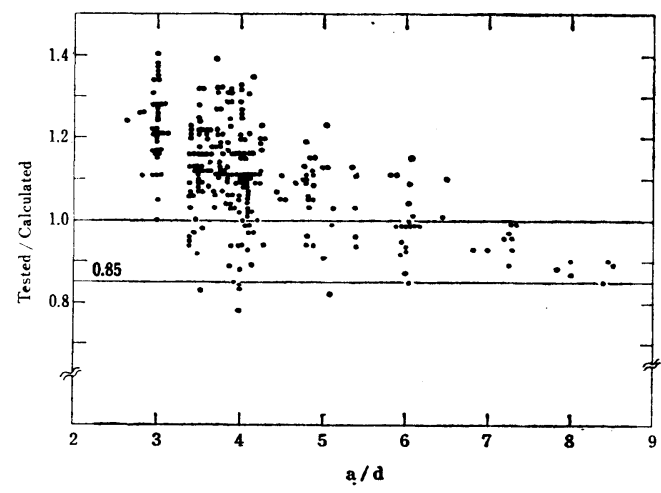

Fig. 9 The relationships between the ratio of shear strength tested to that calculated by Eq. (14).

variation $10.4 \%$. Although it will give a slightly dangerous value in case $a / d$ were to be larger than 5.6, the effect of $a / d$ will be very smaller in this range, since the average ratios for this range is 0.97 with coefficient of variation $7.5 \%$. Furthermore, in such a slender beam there will be very little possibility of failure in shear. Consequently, it is considered that Eq. (14) can safely be used in design. Fig. 8 shows the accumulative frequencies of ratios of shear strengths tested to that calculated by Eq. (10) on a normal probability paper. It may well be assumed that the distribution of the ratios is normal. If the characteristic shear strength is defined as the one with $95 \%$ reliability, $85 \%$ of $f_{v}$ or $f_{v 0}$ in Eq. (14) is to be used for $f_{v k}$ or $f_{v 0 k}$, since the 
coefficient of variation of the ratios of shear strengths tested to that calculated by Eq. (10) is $9.2 \%$ with the average of 1.00 . Actually, among 288 data listed in Table 1, there are only 16 cases $(=5.6 \%)$ in which the shear strengths tested are less than $85 \%$ of the calculated one. Fig. 9 shows that only 5 cases out of 288 are below the characteristic strength $f_{v k}$ calculated by Eq. (15) even when the actual concrete strengths are used insteacl of the characteristic strengths. Therefore, the following equation is proposed for design purposes.

$$
\begin{aligned}
f_{n k} & =f_{v o k}\left(1+\beta_{p}+\beta_{d}\right) \\
f_{n n k} & =0.85 f_{n+1} \\
& =0.17 f_{r \cdot k}^{\prime}{ }^{1 / 3} \quad \text { (in MPa) }
\end{aligned}
$$

\section{(2) Examples of application for specified structures}

Although Eq. (15) is simple enough for practical use, more simplification is possible if structures to which it is applied are limited. For example, applications to T-girder highway bridges and floor slabs of the bridges are described in the section below ${ }^{31)}$.

In simply-supported T-girder highway bridges maximum spans are about $20 \mathrm{~m}$ and are usually less than $15 \mathrm{~m}$, and the span depth ratios are about 10. Therefore, the effective depths are usually less than $1.5 \mathrm{~m}$. Reinforcement ratios of web $\left(p_{w}=A_{s} / b_{w} d, \quad b_{w}\right.$ : width of web) at the span centers are usually higher than about $1.5 \%$, and at the critical sections against shear they are considered to be about $1 \%$ at least. Therefore, for T-girder highway bridges, it is usually safe if Eq. (15) is applied with $d$ equal $1.5 \mathrm{~m}$ and $p_{w}$ equal $1.0 \%$. Similarly, Eq. (15) can be safely applied with $d$ equal to $0.2 \mathrm{~m}$ and $p_{w}$ equal to $1 \%$ for the floor slabs of the bridges in case the slabs are designed as beams against shear.

\section{CONCLUSIONS}

A design equation for shear strength is proposed upon investigation of published test results on shear strengths of reinforced concrete beams without web reinforcement. The proposed equation is deduced based on experiments of beams failing in a diagonal tension mode and subjected to no axial force, and basically, this is also the range of application of the equation.

(1) Shear strengths of reinforced concrete members with shear span-depth ratio larger than 3 and without web reinforcement are estimated well by Eq. (10) which includes concrete strength, reinforcement ratio, effective depth, and shear span-depth ratio in a cumulative form.

(2) For design purposes Eq. (15), which is derived from Eq. (10) by ignoring the effect of shear span-depth ratio, is usually adequate.

(3) If the structures to which the equation is applied are limited, shear strength can be safely expressed by the function of compressive strength of concrete only since the reinforcement ratio and the effective depth are generally within certain limits.

\section{ACKNOWLEDGEMENT}

The research reported in this paper was supported by the Grant-in-Aid for Scientific Research No. 246118 from the Japanese Ministry of Education.

\section{REFERENCES}

1) ASCE-ACI Committee 426: The shear strength of reinforced concrete members, Journal of the structural division, ASCE, ST 6, June, 1973.

2) Fenwick, R. C. and Paulay, T.: Mechanism of shear resistance of concrete beams, Journal of the structural division, ASCE, ST 10, Oct., 1968.

3) Taylor, H. P. J.: The fundamental behavior of reinforced concrete beams in bending and shear, SP-42, ACI, 1974.

4) CEB/FIP: Model code for concrete structures, 1978.

5) ACI: Building code requirement for reinforced concrete (ACI 318-77), 1977

6) BSI: Code of practice for the structural use of concrete (CP 110), Nov., 1972.

7) Cement Association of Japan: Report on the relationship between water-cement ratio and bending or compressive strength of concrete, F-4, May, 1956.

8) Zsutty, T. C.: Beam shear strength prediction by analysis of existing data, Journal of ACI, Nov., 1968.

9) Kennedy, R. P.: A statistical analysis of shear strength of reinforced concrete beams, Ph.D dissertation to Stanford Univ., 1967.

10) Taylor, H. P. J.: Shear strength of large beams, Journal of the structural division, ASCE, ST 11, Nov., 1972.

11) Kani, G. N. J.: How safe are our large reinforced concrete beams?, Journal of ACI, March, 1967.

12) Mattock, A. H.: Diagonal tension cracking in concrete beams with axial forces, Journal of the structural division, ASCE, ST 9, 1969.

13) Placas, A. and Regan, P. E.: Shear failure of reinforced concrete beams, Journal of ACI, Oct., 1971.

14) Ferguson, P. M.: Reinforced concrete fundamentals, 3rd ed., John Wiley and Sons, New York, 1973. 
15) Morrow, J. and Viest, I. M.: Shear strength of reinforced concrete frame members without web reinforcement, Journal of ACI, Mar., 1957.

16) Mathey, R. G. and Watstein, D.: Shear strength of beams without web reinforcement containing deformed bars of different yield strengths, Journal of ACI, Feb., 1963.

17) Kani, G. N. J.: Basic facts concerning shear failure, Journal of ACI, June, 1966.

18) Rajagopalan, K. S. and Ferguson, P. M.: Exploratory shear test emphasizing percentage of longitudinal steel, Journal of ACI, Aug., 1968.

19) Diaz de Cossio, R.: Discussion to "Shear and diagonal tension," by ASCE-ACI Committee 326, Journal of ACI, Sept., 1962.

20) Krefeld, W. J. and C. W. Thurston: Studies of the shear and diagonal tension strength of simply supported reinforced concrete beams, Journal of ACI, Apr., 1966.

21) Moody, K. G., Viest, I. M., Elstner, R. C. and Hognestad, E.: Shear strength of reinforced concrete beams, Pat 1 Tests of simple beams, Journal of ACI, Dec., 1954.

22) Chang, T. S. and Kesler, C. E.: Fatigue behavior of reinforced concrete beams, Journal of ACI, Aug., 1958.

23) Van den Berg, F. J.: Shear strength of reinforced concrete beams without web reinforcement, Part 2 Factors affecting load at diagonal cracking, Journal of ACI, Nov., 1962.

24) Leonhardt, F. and Walther, R.: Beitrage zur Behandlung der Schubprobleme im Stahlbetonbau, Beton- und Stahlbetonbau, 2/1962.

25) Leonhardt, F. and Walther, R.: Beitrage zur Behandlung der Schubprobleme im Stahlbetonbau, Beton- und Stahlbetonbau, 3/1962.

26) Taylor, R.: Some shear tests on reinforced concrete beams without shear reinforcement, Magazine of concrete research, Nov., 1960.

27) Taylor, R. and Brewer, R. S.: The effect of the type of aggregate on the diagonal cracking of concrete beams, Magazine of concrete research, July, 1963.

28) Aster, H. and Koch, R.: Schubtragfahigkeit dicker Stahlbetonplatten, Beton- und Stahlbetonbau, 11/1974.

29) Higai, T.: Fundamental study on shear failure of reinforced concrete Beams, Proceedings of JSCE, No. 279, Nov. 1978.

30) Hedman, O. and Losberg, A.: Design of concrete structures with regard to shear forces, CEB Bulletin D'Information No. 126, June, 1978.

31) Matsuo, J., Shima, T., Fukuyama, T.: Statistical analysis of the highway bridges, Proceedings of JSCE, No. 176, Apr., 1970.

(Received December 14, 1979) 